\title{
Quantifying and reducing uncertainty in life cycle assessment using the Bayesian Monte Carlo method
}

\author{
Shih-Chi Lo, Hwong-wen Ma*, Shang-Lien Lo \\ Graduate Institute of Environmental Engineering, National Taiwan University, 71 Chou-Shan Rd., Taipe, 106, Taiwan
}

Received 15 April 2004; accepted 24 August 2004

\begin{abstract}
The traditional life cycle assessment (LCA) does not perform quantitative uncertainty analysis. However, without characterizing the associated uncertainty, the reliability of assessment results cannot be understood or ascertained. In this study, the Bayesian method, in combination with the Monte Carlo technique, is used to quantify and update the uncertainty in LCA results. A case study of applying the method to comparison of alternative waste treatment options in terms of global warming potential due to greenhouse gas emissions is presented. In the case study, the prior distributions of the parameters used for estimating emission inventory and environmental impact in LCA were based on the expert judgment from the intergovernmental panel on climate change (IPCC) guideline and were subsequently updated using the likelihood distributions resulting from both national statistic and site-specific data. The posterior uncertainty distribution of the LCA results was generated using Monte Carlo simulations with posterior parameter probability distributions. The results indicated that the incorporation of quantitative uncertainty analysis into LCA revealed more information than the deterministic LCA method, and the resulting decision may thus be different. In addition, in combination with the Monte Carlo simulation, calculations of correlation coefficients facilitated the identification of important parameters that had major influence to LCA results. Finally, by using national statistic data and site-specific information to update the prior uncertainty distribution, the resultant uncertainty associated with the LCA results could be reduced. A better informed decision can therefore be made based on the clearer and more complete comparison of options.
\end{abstract}

(C) 2004 Elsevier B.V. All rights reserved.

Keywords: Bayesian Monte Carlo simulation; Life cycle assessment; Probabilistic uncertainty analysis; Coefficients of variation

* Corresponding author. Tel.: +88622363 0406; fax: +8862 23928830.

E-mail address: hwma@ntu.edu.tw (H. Ma).

\section{Introduction}

The life cycle assessment (LCA) is widely used to evaluate environmental performance of products or service because it tends to be holistic, systematic, and multidisciplinary (Ayres, 1995; Miettinen and Hamalainen, 1997; Tukker, 2002). Conversely, the LCA has 
limitations such as the subjective choices and assumptions, the lack of potential impact models, the accuracy of available data, and the uncertainty in the impact results (ISO, 1997). Some researchers also indicated that the utility of conducting LCA studies have been questioned by LCA practitioners, and future studies of LCA will focus on some significant issues, such as the appropriate level of sophistication, the type of modeling, and the uncertainty analysis (U.S. EPA, 2000). Traditionally, the LCA (inventory and impact assessment) is a deterministic model used for estimating the potential impacts associated with a product. However, the LCA's primary weakness lies in its improper treatment of the uncertainty resulting from the sparse and imprecise nature of available information and the simplified model assumptions. The LCA results are often determined by limited data with unknown reliability. Arguments often arise when the assessment results of different options are similar, inasmuch as the reliability of the assessment is not well understood. For instance, Jimenez-Gonzalez and Overcash (2000) have shown that the variability of estimated emissions to the atmosphere, waterborne, and solid waste are approximately $50-150 \%, 1000 \%$, and $30 \%$, respectively, comparing the life cycle inventory (LCI) results for refinery products among several available databases.

Due to the recognition of importance of uncertainty, several previous studies have addressed the classification of uncertainty and variability in LCA (e.g., see Owens, 1996; Huijbregts, 1998). Statistical methods have also been applied to identify the sensitivity of the LCI data (Heijungs, 1996; Kennedy et al., 1997; Steen, 1997). However, the overall uncertainty of LCA results has not been well quantified. To this end, the uncertainties involved in each stage of LCA need to be integrated, and the relative importance of different sources of uncertainties need to be estimated. Only with the information provided can users of LCA results have a good understanding of the reliability and then make informed decisions on option selection or further data collection.

As a tool of uncertainty analysis, the Monte Carlo simulation is a widely used method to perform error propagation for model parameters (McKone, 1989; Bergin et al., 1999; Hertwich et al., 2000; Huijbregts et al., 2000; Goovaerts et al., 2001; Dubus et al.,
2003). In the traditional applications of the Monte Carlo method, the distributions of uncertain parameters have to be given explicitly. In contrast, by combining the Bayesian inference with Monte Carlo simulation, the information input to Monte Carlo simulation can be updated and importance assessed. Hence, the Bayesian inference is considered to improve analysis of LCA uncertainties arising from the lack of knowledge, and it offers a framework to combine judgmental information with observational data in the estimation of uncertain parameters.

In literature, two Bayesian methods, the Bayesian Monte Carlo (BMC) and the Markov Chain Monte Carlo (MCMC) method, have been applied to ecological and environmental modeling (e.g., see Bergin and Milford, 2000; Borsuk et al., 2001). In the research related to water quality simulation, future sea rise prediction, risk assessment, and ground water flow prediction, the Bayesian Monte Carlo method has been used to incorporate experts' judgment and to update uncertainty associated with the observational data (Dilks et al., 1992; Patwardhan and Small, 1992; Brand and Small, 1995; Sohn et al., 2000). Such uncertainty analysis using the Bayesian Monte Carlo approach has not been well applied to life cycle assessment.

This study applies the Bayesian Monte Carlo approach to update the uncertainty and to improve the reliability of LCA of a simplified municipal waste management issue in Taiwan. The study's purpose is threefold: first, to perform uncertainty analysis that adds uncertainty information to traditional LCA decision to understand the importance of uncertainty; second, to identify key parameters that have major influence on LCA results; and lastly, to update and reduce uncertainty of LCA results with statistic and site-specific information.

\section{Materials and methods}

\subsection{LCA and waste management system}

Because of limited land availability for waste disposal, incineration has replaced landfill as the most important waste management method in Taiwan, accommodating more than $90 \%$ of total municipal wastes. Whether the shift from landfill to incineration 
is beneficial to the environment has been an important issue of waste management policy. The comparison of the different municipal waste treatment processes has significant implication on environmental policy. This issue has to be addressed in terms of cost, health risk, and environmental sustainability. As a case study on exploring uncertainty of LCA, the waste management issue is simplified and assessed by using LCA to estimate global warming potential.

The general framework of LCA is composed of four phases: goal and scope definition, inventory analysis, impact assessment, and interpretation, according to the Society of Environment Toxicology and Chemistry guideline (SETAC, 1993) and the International Standard ISO 14040 series (ISO, 1997, 1998, 2000). In the phase of goal and scope definition, the entire life cycle of a product or process includes the stages from extraction of raw materials through manufacturing, transportation, and consumption to waste disposal. Complete system boundaries of the municipal solid waste (MSW) management system would take into consideration the stages from collection of households to disposal, including the environmental impacts from transportation and unit processes with energy recovery (Hunt, 1995; Craighill and Powell, 1996; Finnveden and Ekvall, 1998; Harrison et al., 2000; Thorneloe et al., 2002).

In the case study, the system is simplified and defined only by comparing emissions of waste treatment options between landfill and incineration. By assuming that the transportation distance of waste collection vehicles needed for landfill and incineration is the same, the emissions from collection and transportation of waste are considered to be the indirect emissions and not included in this simplified case. However, energy recovery is included with the combustion of municipal solid waste to substitute for the fossil fuel-based electrical energy because all the incinerators in Taiwan have energy recovery.

The LCA is used to evaluate the total environmental burden from a number of different impact categories (e.g., global warming, acidification, eutrophication, etc.). To further simplify the case, only global warming potential is considered. The functional unit is chosen to account for greenhouse gases emissions produced per tonne of waste. Carbon dioxide is chosen to be the reference gas of global warming potential (GWP), and GWP weighted emissions are measured in kilograms of $\mathrm{CO}_{2}$ equivalent per tonne of waste. The inventory analysis and impact assessment phases are described as follows.

\subsubsection{Inventory analysis}

The inventory data, which contain energy, materials, water pollutant discharges, air pollutant emissions, wastes, and other byproducts, are collected depending on the concerned environmental issues, such as resources, natural environment, and human health. The emissions of greenhouse gases from municipal waste treatment have been estimated using the chemical component analysis (e.g., see Hunt, 1995), the chemical elemental analysis (e.g., see Harrison et al., 2000), and the intergovernmental panel on climate change (IPCC) method (IPCC, 1996).

The IPCC method is used to estimate the emissions of greenhouse gases from alternative waste treatment methods in this study. The emissions from the anaerobic decomposition of waste in landfills are methane and carbon dioxide. The methane but not carbon dioxide in the inventory from landfill is included. The methane is regarded as the anthropogenic greenhouse gas because it is not emitted if the waste is decomposed in aerobic situation. However, the carbon dioxide is excluded because it could also be produced through natural decomposition. The methane produced from the anaerobic decomposition of organic waste disposed in landfill is estimated as follows:

$\mathrm{CH}_{4}$ emissions $=\left[\mathrm{MSW}_{\mathrm{T}} \cdot \mathrm{MSW}_{\mathrm{F}} \cdot \mathrm{L}_{\mathrm{o}}-\mathrm{R}\right] \cdot(1-\mathrm{OX}) \cdot 10^{3}$

where $\mathrm{MSW}_{\mathrm{T}}$ is the total municipal solid waste (MSW) generated (tonne/year); $\mathrm{MSW}_{\mathrm{F}}$ is the fraction of MSW disposed at solid waste disposal sites; $L_{\mathrm{o}}$ is the methane generation potential $\left(L_{\mathrm{o}}=\mathrm{MCF} \cdot \mathrm{DOC}\right.$. $\mathrm{DOC}_{\mathrm{F}} \cdot \mathrm{F} \cdot 16 / 12 ; \mathrm{kg} \mathrm{CH} / \mathrm{kg}$ waste); MCF is the methane correction factor of landfill gas (\%); DOC is the fraction of degradable organic carbon (DOC= $0.4 A+0.17 B+0.15 C+0.3 D ; \mathrm{kg} \mathrm{C} / \mathrm{kg}$ waste); $A, B, C$, and $D$ represent the fraction of paper and textiles, garden waste, food waste, and wood, respectively. $\mathrm{DOC}_{\mathrm{F}}$ is the fraction of landfill gas generation from DOC; $F$ is the fraction by volume of $\mathrm{CH}_{4}$ in landfill gas; $16 / 12$ is the conversion factor from $\mathrm{C}$ to $\mathrm{CH}_{4} ; R$ is the $\mathrm{CH}_{4}$ recovered (tonne $\mathrm{CH}_{4} /$ year); $\mathrm{OX}$ is the oxidation factor (\%). 
In this study, the methane recovery is excluded because most landfills have no energy recovery devices in Taiwan. The oxidation factor reflects the amount of $\mathrm{CH}_{4}$ from landfill, which is oxidized in the soil covering the waste. The landfill is well managed in Taiwan, and thus, the value of oxidation factor is 0.1 according to the IPCC guidelines (IPCC, 2001a).

Incineration of waste produces emissions of carbon dioxide and nitrous oxide. Emissions of $\mathrm{CH}_{4}$ are not likely to be significant because of the high temperature of combustion conditions in incinerators. Normally, the emissions of $\mathrm{CO}_{2}$ from waste incineration are significantly greater than those of $\mathrm{N}_{2} \mathrm{O}$. In most LCAs, the $\mathrm{CO}_{2}$ emissions arising from the incineration of biological carbon in waste are excluded because the amount of $\mathrm{CO}_{2}$ will be balanced automatically by nature. Hence, only the $\mathrm{CO}_{2}$ emissions from fossil carbon are included. The carbon dioxide is estimated from waste incineration as follows:

$\mathrm{CO}_{2}$ emissions $=\mathrm{IW} \cdot[\mathrm{CCW} \cdot \mathrm{FCF} \cdot \mathrm{EF}-\mathrm{R}] \cdot(44 / 12) \cdot 10^{3}$

where IW is the amount of incinerated waste (tonne/ year); $\mathrm{CCW}$ is the fraction of carbon content in waste ( $\mathrm{kg} \mathrm{C} / \mathrm{kg}$ waste); FCF is the fraction of fossil carbon in total carbon (\%); EF is the burn-out efficiency of combustion of incinerators for waste; $R$ is the avoided electric utility carbon emissions due to energy recovery from incinerated waste $(R=\mathrm{H} \cdot \mathrm{CS} \cdot \mathrm{CC} ; \mathrm{kg} \mathrm{C} / \mathrm{kg}$ waste); $H$ is the energy content of incinerated waste (million $\mathrm{Btu} /$ tonne waste); $\mathrm{CS}$ is the combustion system efficiency of incinerator (\%); $\mathrm{CC}$ is the carbon coefficient (tonne carbon equivalents/million Btu of electricity delivered); $44 / 12$ is the conversion factor from $\mathrm{C}$ to $\mathrm{CO}_{2}$.

The item $R$ in Eq. (2) is estimated according to the method of US Environmental Protection Agency (U.S. EPA, 2002). The combustion of municipal solid waste with energy recovery in an incinerator results in avoided carbon dioxide emissions at utility facilities because it is assumed that the energy recovered by an incinerator replaces electric utility generation.

The nitrous oxide is estimated from waste incineration as follows:

$\mathrm{N}_{2} \mathrm{O}$ emissions $=\mathrm{IW} \times \mathrm{EC}_{\mathrm{i}} \times \mathrm{FGV}_{\mathrm{i}} \times 10^{-6}$

where IW is the amount of incinerated waste (tonne/ year); $\mathrm{EC}_{\mathrm{i}}$ is the $\mathrm{N}_{2} \mathrm{O}$ emission concentration in flue gas from waste (ppm); $\mathrm{FGV}_{\mathrm{i}}$ is the flue gas volume by amount of incinerated waste $\left(\mathrm{M}^{3} /\right.$ tonne).

Barton and Atwater (2002) have presented a simplified conceptualization of waste management, in which any flows of $N$-reactants (e.g. $\mathrm{NO}_{x}$ ) out of waste management system needed to be considered as potential sources of nitrous oxide. In this study, the data of nitrous oxide is estimated using that of nitrogen oxides $\left(\mathrm{NO}_{x}\right)$ due to lack of information in Taiwan.

\subsubsection{Impact assessment}

The life cycle impact assessment is used to evaluate the significance of potential environmental impact associated with the emission inventory. In other words, the LCA results are calculated to present a worst case scenario. The impact assessment consists of three elements: classification, characterization, and weighting. The inventory data are grouped by impact categories in the classification step. In subsequent steps, the relative contribution of each environmental impact is characterized. The characterization can be performed using the equivalent factors are based on the approach of marginal change in most LCA studies. Under the assumptions of a relatively small value of the change and well-behaved derivatives, it is possible to reduce the nonlinear relationship to approximation of equivalent factors (Heijungs et al., 2003, 1999). In other words, the individual products always can have very minor marginal changes in emission factors; therefore, it is reasonable to assume linearity for the small change. Based on the marginal approach, the environmental impacts can be calculated utilizing the equivalent assessment model as follows:

$C_{\mathrm{i}}=\sum_{\mathrm{j}} C_{\mathrm{i}, \mathrm{j}}=\sum_{\mathrm{j}} q_{\mathrm{i}, \mathrm{j}} \times e_{\mathrm{i}, \mathrm{j}}$

where $C_{\mathrm{i}}$ is the impact category $i ; C_{\mathrm{i}, \mathrm{j}}$ is the impact category $i$ as a result of emission type $j ; q_{\mathrm{i}, \mathrm{j}}$ is the amount of emission type $j$ for impact category $i ; e_{\mathrm{i}, \mathrm{j}}$ is the characterization coefficient (i.e., the equivalent factor above) of emission type $j$ for impact category $i$.

The environmental burden of global warming potential results from the total greenhouse gases emissions of alternative waste treatment methods. The relative global warming potential (i.e., $e_{i, j}$ ) for greenhouse gases $\mathrm{CO}_{2}, \mathrm{CH}_{4}$ and $\mathrm{N}_{2} \mathrm{O}$ is expressed on the same mass of carbon dioxide on a 100 -year basis, which by definition of GWP is 1 for $\mathrm{CO}_{2}, 21$ for $\mathrm{CH}_{4}$, 
and 310 for $\mathrm{N}_{2} \mathrm{O}$ (IPCC, 1995; Cushman and Jones, 2002). The relative GWP value is recommended as 1:23:296 by the third assessment report of the IPCC (IPCC, 2001b).

\subsection{Probabilistic uncertainty analysis and Bayesian Monte Carlo method}

The uncertainties of LCA arise from inventory data estimation, model's assumption, and subjective judgment. In this case study, the uncertainties of parameters used in estimating greenhouse gas inventory and global warming potential are considered and analyzed using Bayesian Monte Carlo method. The BMC approach consists of Monte Carlo technique and Bayesian inference. In the first part of the method, the Monte Carlo technique was used to convert the deterministic LCA model to a probabilistic model and to forecast the entire range of likely observations in a given situation. The procedure of Monte Carlo technique is described as follows.
First, the uncertainty characterization including means and standard deviations for the parameters in life cycle inventory estimation was adapted from IPCC guideline (IPCC, 2001a). According to the local statistic data of the year 2002 in Taiwan, the prior distributions were selected. For example, the means of the degradable organic carbon were estimated by the physical composition (e.g., textiles, foods, and garden trimmings) of municipal solid waste in the statistic report of Taiwan Environmental Protection Administration (Taiwan EPA). Similarly, the carbon content of waste was estimated by the chemical element analysis of solid waste. Then, the two parameters were assumed normally distributed based on the underlying statistic data. The $\mathrm{N}_{2} \mathrm{O}$ emission concentration in flue gas was collected from 17 incinerators and assumed lognormally distributed based on the data. The other parameters were assumed uniformly distributed due to the nature of small variation. It was also assumed that the relative global warming potential coefficients, $e_{\mathrm{i}, \mathrm{j}}$, were uniformly distributed (Table 1). Next, the

Table 1

Summary of prior parameters mean and uncertainty distributions in life cycle assessment

\begin{tabular}{|c|c|c|c|}
\hline Model parameters and inputs & Mean & Uncertainty distribution & Reference \\
\hline \multicolumn{4}{|l|}{ Parameters of life cycle inventory ${ }^{\mathrm{a}}$} \\
\hline Methane correction factor (MCF [\%]) & 0.90 & Uniform $(0.8,1.0)$ & IPCC (2001a) \\
\hline Degradable organic carbon (DOC [kg C/kg waste]) & 0.18 & Normal $(0.18,0.04)$ & Taiwan EPA (2002) \\
\hline Fraction DOC dissimilated $\left(\mathrm{DOC}_{\mathrm{F}}[\%]\right)$ & 0.55 & Uniform $(0.50,0.60)$ & IPCC (2001a) \\
\hline Fraction by volume of $\mathrm{CH}_{4}$ in landfill gas $(F[\%])$ & 0.50 & Uniform $(0.40,0.60)$ & IPCC (2001a) \\
\hline Oxidation factor $(\mathrm{OX}[\%])$ & 0.10 & Uniform $(0.09,0.11)$ & $\operatorname{IPCC}(2001 \mathrm{a})$ \\
\hline Carbon content of waste (CCW [kg C/kg waste]) & 0.42 & Normal $(0.42,0.08)$ & Taiwan EPA (2002) \\
\hline Fraction of fossil carbon in total carbon (FCF [\%]) & 0.40 & Uniform $(0.30,0.50)$ & IPCC (2001a) \\
\hline Energy content of incinerated waste ( $H$ [million Btu/tonne]) & 6.78 & Normal $(6.78,1.16)$ & Taiwan EPA (2002) \\
\hline Combustion system efficiency of incinerator (CS [\%]) & 0.17 & Uniform $(0.15,0.19)$ & U.S. EPA (2002) \\
\hline $\begin{array}{l}\text { Carbon coefficient }(\mathrm{CC}) \text {, tonne carbon equivalents/million } \\
\text { Btu of electricity delivered }\end{array}$ & 0.081 & Uniform $(0.077,0.085)$ & U.S. EPA (2002) \\
\hline Efficiency of combustion (EF [\%]) & 0.95 & Uniform $(0.91,0.99)$ & $\operatorname{IPCC}(2001 a)$ \\
\hline $\begin{array}{l}\mathrm{N}_{2} \mathrm{O} \text { emission concentration in flue gas from waste } \\
\left(\mathrm{EC}_{\mathrm{i}}[\mathrm{ppm}]\right)\end{array}$ & 104 & Lognormal $(104,46.8)$ & Taiwan EPA (2002) \\
\hline $\begin{array}{l}\text { Flue gas volume by amount of incinerated waste } \\
\qquad\left(\mathrm{FGV}_{\mathrm{i}}\left[\mathrm{M}^{3} / \text { tonne }\right]\right)\end{array}$ & 8000 & Uniform $(7500,8500)$ & Taiwan EPA (2002) \\
\hline \multicolumn{4}{|l|}{ Inputs of relative $G W P$ coefficient ${ }^{\mathrm{b}}$} \\
\hline $\mathrm{CO}_{2}\left(\mathrm{E}_{\mathrm{CO} 2}\right)$ & 1 & Reference gas & \\
\hline $\mathrm{CH}_{4}\left(\mathrm{E}_{\mathrm{CH} 4}\right)$ & 22 & Uniform $(21,23)$ & (IPCC, 1995; 2001b) \\
\hline $\mathrm{N}_{2} \mathrm{O}\left(\mathrm{E}_{\mathrm{N} 2 \mathrm{O}}\right)$ & 303 & Uniform $(296,310)$ & (IPCC, 1995; 2001b) \\
\hline
\end{tabular}


parameters uncertainties were propagated to estimate the overall uncertainties through Eq. (4), using Monte Carlo simulation based on probability density functions (PDFs) of the parameters.

Finally, rank correlation coefficients were calculated along with the Monte Carlo sampling to measure the importance of parameter uncertainty. Considering $n$ pairs of samples from the output and single input denoted as $y_{\mathrm{i}}$ and $x_{\mathrm{i}}$, respectively, for $i=1$ to $n$, the rank correlation coefficient is calculated as follows:

Correlation coefficient

$$
=\frac{\sum_{i}^{n}\left(x_{i}-\bar{x}\right)\left(y_{i}-\bar{y}\right)}{\sqrt{\sum_{i=1}^{n}\left(x_{i}-\bar{x}\right)^{2} \times \sum_{i=1}^{n}\left(y_{i}-\bar{y}\right)^{2}}}
$$

where $\bar{x}$ and $\bar{y}$ are expected values of $x$ and $y$, respectively. We calculated rank correlation coefficients between input parameters and LCA outputs, and the correlation coefficients of all the parameters were squared and normalized to calculate their contribution to the total variance.

In the second part, the uncertainty distributions of inventory parameters adopted from IPCC guideline were treated as the prior distributions. With the Bayesian update procedure, the prior distribution can then be updated to obtain the posterior probability. Given the newly observed data, the posterior probability of each realization of the Monte Carlo simulation can be derived as the following equation (Brand and Small, 1995):

$p_{i}^{\prime}\left(C_{i} \mid O\right)=\frac{L\left(O \mid C_{i}\right) p_{i}\left(C_{i}\right)}{\sum_{i=1}^{N} L\left(O \mid C_{i}\right) p_{i}\left(C_{i}\right)}$

where $p_{i}^{\prime}$ is the posterior probability of the $i$ th Monte Carlo simulation; $L\left(O \mid C_{i}\right)$ is the likelihood of observation $O$ given the model output $C_{i} ; p_{i}\left(C_{i}\right)$ is the prior probability of the $i$ th Monte Carlo simulation; $C_{i}$ is the model output; $O$ is the newly observed data, and $N$ is the number of Monte Carlo realizations. The denominator in Eq. (6) is the normalizing constant $(k)$. The BMC method can be expressed as:

$p_{i}^{\prime}=k L\left(O \mid C_{i}\right) p\left(C_{i}\right)$

The selection of appropriate error structure for the likelihood function is the key consideration for the
BMC method. For this reason, based on an unbiased measurement with a normally distributed error, the likelihood of an observation is given as the following equation:

$$
L\left(O \mid C_{i}\right)=f\left(O-C_{i}\right)=\frac{1}{\sqrt{2 \pi \sigma_{\varepsilon}}} \exp \left(-\frac{1}{2}\left[\frac{O-C_{i}}{\sigma_{\varepsilon}}\right]^{2}\right)
$$

where $\sigma_{\varepsilon}$ is the standard deviation of the observation error. If more than one independent observation is considered, the likelihood in Eq. (8) then becomes the product of the likelihood for the individual observations. The statistical properties of the posterior distribution are calculated in the usual manner using the posterior probability density functions in Eq. (7).

Finally, the coefficient of variation (CV), defined as the ratio of the arithmetic standard deviation of a parameter to arithmetic mean, was used to evaluate the degree of uncertainty reduction of each parameter. In this study, two sources of likelihood distribution were considered. First, to update the prior parameter PDFs using Taiwan national statistic data, the likelihood means and standard deviations were collected from the statistic report of Taiwan EPA (2002). According to the statistical analysis of the governmental data, the means $(\mu)$ and $\mathrm{CV}$ values from year $1992-2002$ were $\mu=0.19 \mathrm{~kg} \mathrm{C} / \mathrm{kg}$ waste, $\mathrm{CV}=0.05$ for degradable organic carbon (DOC), $\mu=0.38 \mathrm{~kg} \mathrm{C} / \mathrm{kg}$ waste, $\mathrm{CV}=0.06$ for carbon content of waste $(\mathrm{CCW})$, and $\mu=6.48$ million Btu/tonne waste, $\mathrm{CV}=0.10$ for energy content of incinerated waste $(H)$. The sample size is 5000 , and the prior distributions are assumed normally distributed. Second, to update the prior parameter PDFs using sitespecific data, the likelihood means and standard deviations were collected from the Pei-Tou and Hsichou incinerators in Taiwan. The two incinerators were chosen because they had the most complete data. The mean value was $98.68 \mathrm{ppm}$, and $\mathrm{CV}$ was 10.33 for the $\mathrm{EC}_{\mathrm{i}}$ of Pei-Tou incinerator of the year 1999-2003, and the mean was $105 \mathrm{ppm}$ and $\mathrm{CV} 3$ for $\mathrm{ECi}$ of Hsichou incinerator. The sample size is 5000, and the prior distribution is assumed lognormally distributed because the range of variance is over $30 \%$. 


\section{Results and discussion}

\subsection{LCA results with and without uncertainty analysis}

Table 2 shows the greenhouse gas inventory including $\mathrm{CH}_{4}, \mathrm{CO}_{2}$, and $\mathrm{N}_{2} \mathrm{O}$ emissions and the GWP values for alternative waste treatment options without considering uncertainty. Calculated with mean values of parameters without incorporation of uncertainty, the total GWP of landfill, $1176.12 \mathrm{~kg}$ of $\mathrm{CO}_{2}$ equivalents per tonne of waste, was higher than that of the waste incineration, $494.97 \mathrm{~kg}$ of $\mathrm{CO}_{2}$ equivalents per tonne of waste. The reason that the GWP of landfill is higher than incineration is because the relative GWP coefficient of $\mathrm{CH}_{4}$ is 22 times that of $\mathrm{CO}_{2}$. In other words, methane is a stronger greenhouse gas than $\mathrm{CO}_{2}$. In comparison with previous research, in some cases (e.g., plastics wastes), the emissions of landfill were estimated to be less than those of incineration (U.S. EPA, 2002). However, in the research of Barton and Atwater (2002), the results showed that the emissions of landfill were more than those of incineration by

Table 2

Comparison of LCA results between alternative waste treatment methods of year 2002 in Taiwan with and without uncertainty analysis

\begin{tabular}{|c|c|c|c|}
\hline \multirow[t]{2}{*}{$\begin{array}{l}\text { Greenhouse gas } \\
\text { inventory }\end{array}$} & \multicolumn{2}{|c|}{$\begin{array}{l}\text { Emissions of alternative } \\
\text { waste treatment }{ }^{\mathrm{a}} \\
\text { (kg gas/tonne waste) }\end{array}$} & \multirow[t]{2}{*}{$\begin{array}{l}\text { Relative GWP } \\
\text { coefficient }(\mathrm{kg} \mathrm{CO} 2 \\
\text { equivalent } / \mathrm{kg} \text { gas })\end{array}$} \\
\hline & Landfill & Incineration & \\
\hline $\mathrm{CO}_{2}$ emission & 0 & 242.88 & 1 \\
\hline $\mathrm{CH}_{4}$ emission & 53.46 & 0 & 22 \\
\hline $\mathrm{N}_{2} \mathrm{O}$ emission & 0 & 0.83 & 303 \\
\hline \multicolumn{2}{|c|}{ Life cycle impact assessment } & \multicolumn{2}{|c|}{$\begin{array}{l}\text { GWP of alternative waste } \\
\text { treatment }\left(\mathrm{kg} \mathrm{CO}_{2} \text { equivalents / }\right. \\
\text { tonne waste) }\end{array}$} \\
\hline \multirow{2}{*}{\multicolumn{2}{|c|}{$\begin{array}{l}\text { LCA results without uncertainty } \\
L C A \text { results with uncertainty }{ }^{\mathrm{b}} \\
5 \text { th } \%\end{array}$}} & ty 1176.12 & 494.97 \\
\hline & & 739 & 195 \\
\hline \multicolumn{2}{|l|}{ 50th \% (Median) } & 1158 & 480 \\
\hline \multicolumn{2}{|l|}{ Mean } & 1178 & 491 \\
\hline \multicolumn{2}{|c|}{95 th $\%$} & 1685 & 831 \\
\hline \multicolumn{2}{|c|}{ Standard deviation } & 289 & 192 \\
\hline \multicolumn{2}{|c|}{ Coefficient of variation (CV) } & 0.25 & 0.39 \\
\hline
\end{tabular}

comparing the total greenhouse gas emission resulting from the landfill, incineration, and backyard compost of food waste (Barton and Atwater, 2002). Moreover, according to the US Environmental Protection Agency inventory of greenhouse gas emissions, the landfills are the largest anthropogenic source of methane from waste section in 1999 (Thorneloe et al., 2002). Therefore, the previously estimated GWP value was dependent on the composition of waste and whether the unit process with energy recovery exists. In Taiwan, inasmuch as the food waste $(23 \%)$ is included in mixed municipal solid waste and the incinerators have energy recovery, it is reasonable that the emissions of landfill are greater than those of incineration.

To take into consideration the uncertain parameters in LCA, the Monte Carlo simulation was used to transform the deterministic LCA model to the probabilistic model. Table 2 presents the estimated distributions of LCA results of both waste treatment methods, describing the mean value, standard deviation, and $90 \%$ confidence interval (i.e., 5th percentile and the 95th percentile). The confidence interval supplementary to LCA results should reflect the simulated information about uncertainty of parameters and inputs. It was also found that the total $\mathrm{CV}$ value of GWP distribution was 0.25 for landfill and 0.39 for incineration. In comparison with the assessment results based on the deterministic LCA model, the probabilistic model obviously reveals more information and characterizes the underlying uncertainties. With uncertainty information provided, it was found that the ranges of possible GWP values for both treatment methods were overlapping. The superiority of incineration over landfill in terms of GWP was not as distinct as it looked under the deterministic model. The decision of choosing the best waste treatment method based on the two analyses may thus be different.

Table 3 presents the contribution of each parameter's uncertainty to the overall variance of the GWP estimates. The parameters with contribution of uncertainty to total variation of landfill GWP that was greater than 5\% was DOC, $F$, and MCF. As for incineration, the contributions of uncertainties of $\mathrm{CCW}, \mathrm{EC}_{\mathrm{i}}, \mathrm{FCF}$, and $H$ were greater than $5 \%$ of the total uncertainty. Based on the order of contribution to uncertainty, the importance of parameters can be 
Table 3

Contributions of each parameter to the variance of the GWP estimate of alternative waste treatment methods

\begin{tabular}{|c|c|}
\hline Model parameters and inputs & $\begin{array}{l}\text { Variance } \\
\text { contribution }(\%)\end{array}$ \\
\hline \multicolumn{2}{|l|}{ Landfill } \\
\hline Degradable organic carbon (DOC) & 65.5 \\
\hline $\begin{array}{l}\text { Fraction by volume of } \mathrm{CH}_{4} \text { in } \\
\text { landfill gas }(\mathrm{F})\end{array}$ & 20.2 \\
\hline Methane correction factor (MCF) & 6.5 \\
\hline Fraction DOC dissimilated $\left(\mathrm{DOC}_{\mathrm{F}}\right)$ & 3.7 \\
\hline Carbon content of waste $(\mathrm{CCW})$ & 2.0 \\
\hline $\mathrm{E}_{\mathrm{CH} 4}$ & 1.5 \\
\hline Oxidation factor (OX) & 0.2 \\
\hline \multicolumn{2}{|l|}{ Incineration } \\
\hline Carbon content of waste (CCW) & 37.4 \\
\hline $\begin{array}{l}\mathrm{N}_{2} \mathrm{O} \text { emission concentration in flue } \\
\text { gas from waste }\left(\mathrm{EC}_{\mathrm{i}}\right)\end{array}$ & 28.6 \\
\hline $\begin{array}{l}\text { Fraction of fossil carbon in total } \\
\text { carbon (FCF) }\end{array}$ & 22.3 \\
\hline Energy content of incinerated waste $(\mathrm{H})$ & 8.7 \\
\hline $\begin{array}{l}\text { Combustion system efficiency of } \\
\text { incinerator (CS) }\end{array}$ & 1.2 \\
\hline Degradable organic carbon (DOC) & 0.9 \\
\hline
\end{tabular}

It is calculated that the relation between $\mathrm{CCW}$ and $\mathrm{DOC}$ parameters were positive correlation and the coefficient value was 0.18 according to the statistic data from years 1992-2002 in Taiwan (EPA, 2002). The sample size of Monte Carlo simulation is 5000.

identified. For those parameters that have large contribution and are thus important, more information should be collected to reduce the overall LCA uncertainty efficiently and to obtain more accurate LCA results.

\subsection{Updating uncertainty using statistic and site-specific data}

Table 4 contrasts the prior and posterior means and $\mathrm{CV}$ values of the important parameters involved in the inventory and impact assessment phases. The smaller $\mathrm{CV}$ values of posterior parameter distributions clearly showed that incorporation of more precise likelihood information reduced uncertainty. For example, it was found that the $\mathrm{CV}$ value (0.05) of posterior DOC probability distribution was less than $1 / 4$ of the prior value; and the results of $\mathrm{CCW}$ were similar. The posterior distributions of $\mathrm{DOC}$ and $\mathrm{CCW}$ were significantly affected by the likelihood distributions because the likelihood distributions were more precise than the prior distributions. Fig. 1 illustrates an example of comparison of the prior and posterior PDFs for the parameter of $\mathrm{N}_{2} \mathrm{O}$ emission concentration in flue gas of waste incineration $\left(\mathrm{EC}_{\mathrm{i}}\right)$. Incorporating site-specific data from the two chosen incinerators, which produced the posterior PDFs, it is shown that the posterior distribution is narrower than the prior distribution. It was apparent that the uncertainty associated with the $\mathrm{EC}_{\mathrm{i}}$ value had been reduced significantly because more precise sitespecific data were included. Some parameters (e.g., $\mathrm{MCF}, \mathrm{DOC}_{\mathrm{F}}, F, \mathrm{OX}, \mathrm{EF}, \mathrm{CS}$, and SS) do not show significant reduction in posterior uncertainties of compared to prior distribution because, in these cases, the prior uniform distribution had a stronger effect than the likelihood distribution.

Table 4

Summary of prior, likelihood, and posterior distributions for important parameters and the changes in CV values

\begin{tabular}{|c|c|c|c|c|c|c|c|}
\hline \multirow[t]{2}{*}{ Model parameters } & \multicolumn{2}{|l|}{ Prior } & \multicolumn{2}{|c|}{ Likelihood } & \multicolumn{2}{|c|}{ Posterior } & \multirow{2}{*}{$\begin{array}{l}\text { \%Change } \\
\text { in } \mathrm{CV}\end{array}$} \\
\hline & Mean & $\mathrm{CV}^{\mathrm{a}}$ & Mean & $\mathrm{CV}$ & Mean & $\mathrm{CV}$ & \\
\hline $\begin{array}{l}\text { Degradable organic carbon (DOC), } \\
\mathrm{kg} \mathrm{C} / \mathrm{kg} \text { waste }\end{array}$ & 0.18 & 0.20 & 0.19 & 0.05 & 0.19 & 0.05 & -74.93 \\
\hline $\begin{array}{l}\text { Carbon content of waste }(\mathrm{CCW}) \text {, } \\
\mathrm{kg} \mathrm{C} / \mathrm{kg} \text { waste }\end{array}$ & 0.42 & 0.20 & 0.38 & 0.06 & 0.38 & 0.05 & -74.54 \\
\hline $\begin{array}{l}\text { Energy content of incinerated } \\
\text { waste }(\mathrm{H}), \text { million Btu/tonne }\end{array}$ & 6.78 & 0.17 & 6.48 & 0.10 & 6.52 & 0.08 & -49.81 \\
\hline \multicolumn{8}{|l|}{$\begin{array}{l}\mathrm{N}_{2} \mathrm{O} \text { emission concentration in } \\
\text { flue gas from waste }\left(\mathrm{EC}_{\mathrm{i}}\right) \text {, ppm }\end{array}$} \\
\hline Pei-Tou incinerator & 104 & 0.45 & 98.68 & 0.10 & 97.38 & 0.09 & -68.99 \\
\hline Hsichou incinerator & 104 & 0.45 & 105 & 0.03 & 104.96 & 0.03 & -94.31 \\
\hline
\end{tabular}

${ }^{a}$ The coefficient of variation $(\mathrm{CV})$ is the ratio of the arithmetic standard deviation of a parameter to arithmetic mean. The sample size is 5000 . 

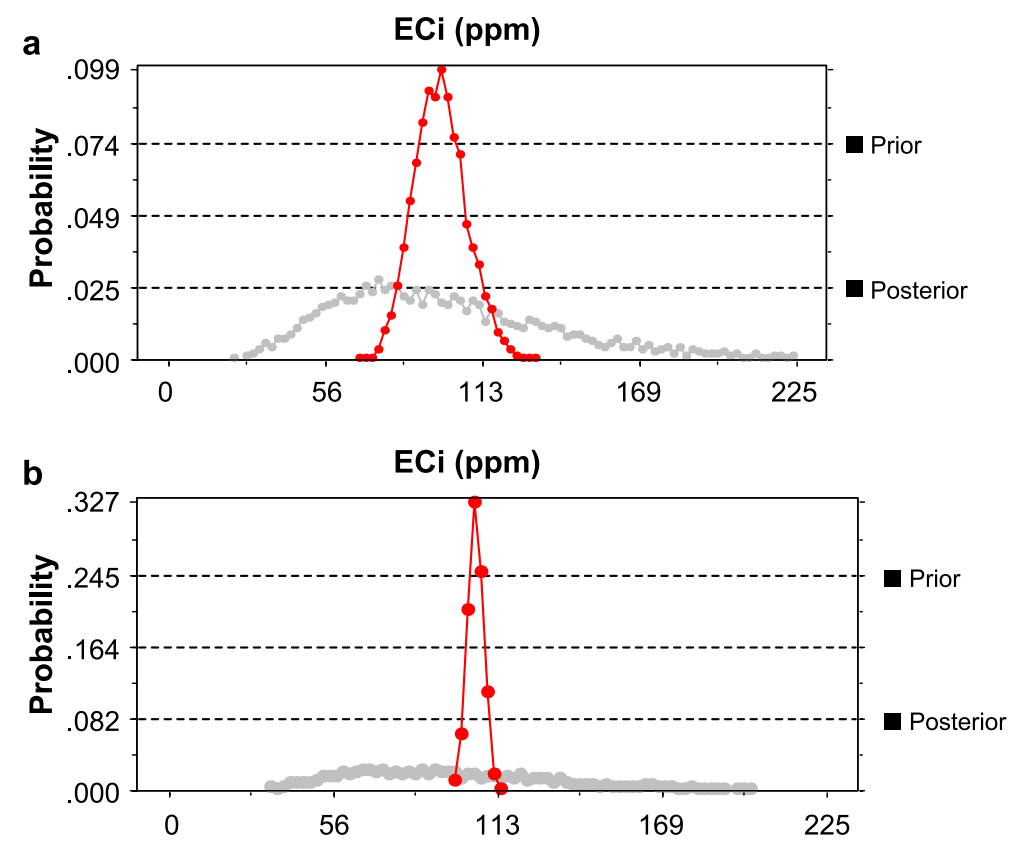

Fig. 1. Comparison of prior and posterior distributions of $\mathrm{EC}_{\mathrm{i}}$ parameter updated using site-specific data for waste incineration. (a) Prior mean $=104 \mathrm{ppm}, \mathrm{CV}=45 \%$; posterior mean $=97.38 \mathrm{ppm}, \mathrm{CV}=9 \%$ for Pei-Tou incinerator. (b) Posterior mean=104.96 ppm, $\mathrm{CV}=3 \%$ for Hsichou incinerator.

Fig. 2 shows the results (distributions $A$ and $B$ ) of prior PDFs of the GWP for alternative waste treatment methods. The distributions for the two studied treatment methods were found partly overlapped as stated previously. Fig. 2 also shows the posterior distributions $(\mathrm{C}$ and $\mathrm{D})$ of the two waste treatment methods. It is important to note that the distinction between the posterior probability distributions of LCA results of landfill and incineration was much clearer than that of the prior distribution.
Compared with the prior distributions, the uncertainties of posterior distributions were reduced by $40 \%$ for landfill and $46 \%$ for incineration. In this case study, the addition of national statistic and sitespecific information to prior probability distributions was shown to facilitate the differentiation of the two waste treatment methods. Based on the same approach with yearly information, the prior and posterior distributions of GWP for each year can be estimated.

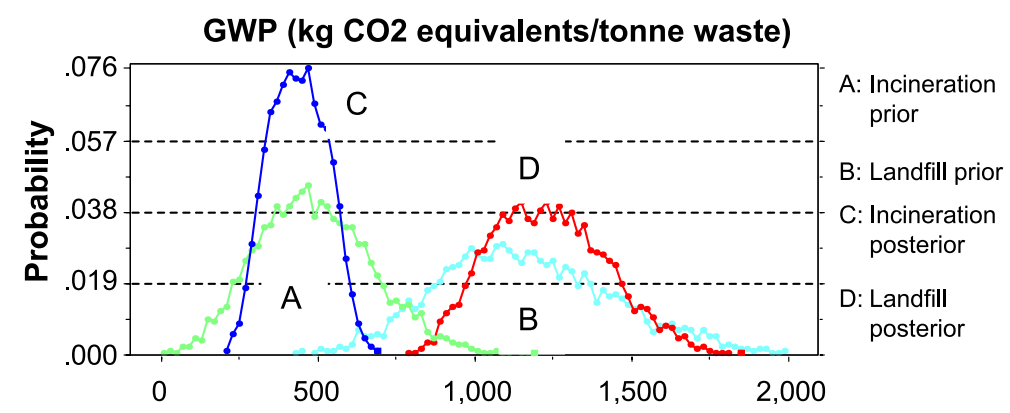

Fig. 2. Comparison of prior and posterior distributions of GWP. (A) Prior mean=494, standard deviation=192, CV=0.39 for incineration. $(B)$ Prior mean=1176, standard deviation $=297, C V=0.25$ for landfill. $(C)$ Posterior mean=438, standard deviation $=92, \mathrm{CV}=0.21$ for incineration. (D) Posterior mean=1241, standard deviation $=189, \mathrm{CV}=0.15$ for landfill. 
The advantages of the BMC method are the ability to include prior information, the framework of incorporation into an information formal decision analysis, the explicit treatment of uncertainty, and the straightforward ability to integrate new information in contexts. However, the BMC approach has some problems associated with the sampling technique. Qian et al. (2003) indicated that the sampling performance of the BMC method is inefficient and does not converge toward the most probable region of the posterior distribution. Regarding the limitation, the sampling space and the model structure should be considered in this study. In principle, the law of large numbers ensures that the approximation can be made more accurate by increasing the sample size of Monte Carlo simulation, which was chosen to be 5000 in this study. Also, the impact assessment model in the present study is a simple linear model. Therefore, the BMC method applying to LCA can be well simulated in large samples and simple linear impact assessment model.

The BMC method in this case study has been shown to be useful for quantifying and reducing parameter uncertainty in LCA. It is important to note that other types of uncertainty need to be considered, such as the structural uncertainties that include different assumptions in parameters and choice of impact models. For example, Hertwich et al. (2000) presented a framework to account for uncertainty in LCA that distinguishes among decision rule uncertainty, model uncertainty, and uncertainty and variability in input parameters. It indicated that different model choices could lead to more variations in the final results of an LCA study than the differences between the alternatives. However, there is no standard method for quantifying all types of uncertainty. In fact, the limitation of structural uncertainty need further research. In this study, the purpose is to present the BMC method used in LCA and does not analyze the structural uncertainties.

\section{Conclusions}

The problem of uncertainty may limit the use of life cycle assessment results for decision making unless the uncertainty is integrated into the evaluation process. Therefore, the probabilistic uncertainty anal- ysis is incorporated into LCA, so that the associated reliability can be understood, and the LCA results will not be misused. Based on the Monte Carlo simulation of probabilistic LCA, the importance of parameters' uncertainty in LCA can be identified and whether and how more information should be collected can also be determined. The Bayesian Monte Carlo method is a useful tool for quantifying and reducing uncertainty in LCA. The resulting posterior uncertainty reflects both the model's performance of LCA and subjective judgments (e.g., expert judgment) about uncertainty in model parameters. Moreover, it provides a methodology for assessing the value of additional information in decision making. With appropriate use of this method in combination with suitable information, the reliability of LCA can be enhanced. The study has demonstrated the utility of BMC method for quantifying and reducing parameter uncertainty in LCA. More research is needed to explore different types of uncertainty.

\section{References}

Ayres RU. Life cycle analysis: a critique. Resour Conserv Recycl 1995;14:199-223.

Barton PK, Atwater JW. Nitrous oxide emissions and the anthropogenic nitrogen in wastewater and solid waste. J Environ Eng 2002;128(2): $137-50$.

Bergin MS, Milford JB. Application of Bayesian Monte Carlo analysis to a lagrangian photochemical air pollution model. Atmos Environ 2000;34:781-92.

Bergin MS, Noblet GS, Petrini K, Dhieux JR, Milford JB, Harley RA. Formal uncertainty analysis of a lagrangian photochemical air pollution model. Environ Sci Technol 1999;33(7):1116-26.

Borsuk ME, Higdon D, Stow CA, Reckhow KH. A Bayesian hierarchical model to predict benthic oxygen demand from organic matter loading in estuaries and coastal zones. Ecol Model 2001;143:165-81.

Brand KP, Small MJ. Updating uncertainty in an integrated risk assessment: conceptual framework and methods. Risk Anal 1995;15(6):719-31.

Craighill AL, Powell JC. Life cycle assessment and economic evaluation of recycling: a case study. Resour Conserv Recycl 1996; 17:75-96.

Cushman RM, Jones SB. The relative importance of sources of emissions: comparison of global through subnational perspectives. Environ Manage 2002;29(3):360-72.

Dilks DW, Canale RP, Meier PG. Development of Bayesian Monte Carlo techniques for water quality model uncertainty. Ecol Model 1992;62:149-62.

Dubus IG, Brown CD, Beulke S. Sources of uncertainty in pesticide fate modeling. Sci Total Environ 2003;317:53-72. 
Finnveden G, Ekvall T. Life cycle assessment as a decision support tool- the case of recycling versus incineration of paper. Resour Conserv Recycl 1998;24:235-56.

Goovaerts P, Semrau J, Lontoh S. Monte Carlo analysis of uncertainty attached to microbial pollutant degradation rates. Environ Sci Technol 2001;35:3924-30.

Harrison KW, Dumas RD, Barlaz MA, Nishtala SR. A life-cycle inventory model of municipal solid waste combustion. J Air Waste Manage Assoc 2000;50:993-1003.

Heijungs R. Identification of key issues for further investigation in improving the reliability of life-cycle assessments. J Clean Prod 1996;4(3-4):159-66.

Heijungs R, Huijbregts MAJ. Threshold-based life cycle impact assessment and marginal change: incompatible, CML-SSP Working Paper 99.002. Centre of Environmental Science (CML), Leiden University, Netherlands; 1999.

Heijungs R, Goedkoop M, Struijs J, Effting S, Sevenster M, Huppes G. Towards a life cycle impact assessment method which comprises category indicators at the midpoint and the endpoint level-report of the first project phase: design of the new method. Centre of Environmental Science (CML), Leiden University, Netherlands; 2003.

Hertwich EG, McKone TE, Pease WS. A systematic uncertainty analysis of an evaluative fate and exposure model. Risk Anal 2000;20(4):437-52.

Huijbregts MAJ. Application of parameter uncertainty and variability in LCA: Part 1 A general framework for the analysis of uncertainty and variability in life cycle assessment. Int J LCA 1998;3(5):273-80.

Huijbregts MAJ, Thissen U, Jager T, van de Meent D, Ragas AMJ. Priority assessment of toxic substances in life cycle assessment: Part 2 Assessing parameter uncertainty and human variability in the calculation of toxicity potential. Chemosphere 2000;41: $575-88$.

Hunt RG. LCA considerations of solid waste management alternatives for paper and plastics. Resour Conserv Recycl 1995; $14: 225-31$.

Intergovernmental Panel on Climate Change (IPCC). Climate change 1995: The science of climate change. Contribution of working group I to the second assessment report of the IPCC. UK: Cambridge University Press; 1995.

Intergovernmental Panel on Climate Change (IPCC). Revised 1996 IPCC guidelines for national greenhouse gas inventories; 1996.

Intergovernmental Panel on Climate Change (IPCC) RG. Good practice guidance and uncertainty management in national greenhouse gas inventories; 2001a.

Intergovernmental Panel on Climate Change (IPCC). Technical summary: a report accepted by working group I of the IPCC but not approved in detail. A product resulting from the third assessment report of working group I of the intergovernmental panel on climate change; 2001b (January).
International Standardization Organization (ISO). Environmental management-life cycle assessment-principal and framework. ISO 14040. Geneva, Switzerland; 1997.

International Standardization Organization (ISO). Environmental management-life cycle assessment-goal and scope definition and inventory analysis, ISO 14041. Geneva, Switzerland; 1998.

International Standardization Organization (ISO). Environmental management-life cycle assessment-life cycle assessment impact assessment. ISO 14042. Geneva, Switzerland; 2000.

Jimenez-Gonzalez C, Overcash M. Life cycle assessment of refinery products: review and comparison of commercially available databases. Environ Sci Technol 2000;34(22):4789-96.

Kennedy DJ, Montgomery DC, Rollier DA, Keats JB. Assessing input data uncertainty in life cycle assessment inventory model. Int J LCA 1997;2(4):229-39.

McKone TE. Human exposures to chemical through food chains: an uncertainty analysis. Environ Sci Technol 1989;23(9): $1154-1163$

Miettinen P, Hamalainen RP. How to benefit from decision analysis in environmental life cycle assessment (LCA). Eur J Oper Res 1997;102(2):279-94.

Owens JW. LCA impact assessment categories technical feasibility and accuracy. Int J LCA 1996;1(3):151-8.

Patwardhan A, Small MJ. Bayesian methods for model uncertainty analysis with application to future sea rise. Risk Anal 1992; 12(4):513-22.

Qian SS, Stow CA, Borsuk ME. On Monte Carlo methods for Bayesian inference. Ecol Model 2003;159:269-77.

Society of Environment Toxicology and Chemistry (SETAC). Guidelines for life cycle assessment code of practice, Portugal; 1993.

Sohn MD, Small MJ, Pantazidou M. Reducing uncertainty in site characterization using Bayes Monte Carlo methods. J Environ Eng 2000;126(10):893-902.

Steen B. On uncertainty and sensitivity of LCA-based priority setting. J Clean Prod 1997;5(4):255-62.

Taiwan Environmental Protection Administration (Taiwan EPA). Yearbook of environmental protection statistics. Taiwan; 2002. in Chinese.

Tukker A. Life cycle assessment and the precautionary principal. Environ Sci Technol; 2002(Feb.): 71A-5A.

Thorneloe SA, Weitz KA, Nishtala SR, Yarkosky S, Zannes M. The impact of municipal solid waste management on greenhouse gas emissions in the United States. J Air Waste Manage Assoc 2002;52:1000-11.

U.S. Environmental Protection Agency (U.S. EPA). An international workshop on life cycle impact assessment sophistication; 2000. EPA 600-R-00-023.

U.S. Environmental Protection Agency (U.S. EPA). Solid waste management and greenhouse gases: a life-cycle assessment of emissions and sinks; 2002. EPA 530-R-02-006. 